This item was submitted to Loughborough's Research Repository by the author.

Items in Figshare are protected by copyright, with all rights reserved, unless otherwise indicated.

\title{
Value stream mapping to reduce the lead-time of a product development process
}

PLEASE CITE THE PUBLISHED VERSION

http://dx.doi.org/10.1016/j.ijpe.2014.11.002

PUBLISHER

(C) Elsevier

VERSION

AM (Accepted Manuscript)

\section{PUBLISHER STATEMENT}

This work is made available according to the conditions of the Creative Commons Attribution-NonCommercialNoDerivatives 4.0 International (CC BY-NC-ND 4.0) licence. Full details of this licence are available at: https://creativecommons.org/licenses/by-nc-nd/4.0/

\section{LICENCE}

CC BY-NC-ND 4.0

\section{REPOSITORY RECORD}

Tyagi, Satish, Alok K. Choudhary, Xianming Cai, and Kai Yang. 2019. "Value Stream Mapping to Reduce the Lead-time of a Product Development Process". figshare. https://hdl.handle.net/2134/25242. 


\title{
Value stream mapping to reduce lead-time of a product development process
}

\begin{abstract}
Product development (PD) is a broad field of endeavor dealing with the planning, design, creation, and marketing of a new product. This revolutionary research domain has become of paramount importance to beat the competition for multidisciplinary products which are larger in size and have a longer development time. The main focus of this paper is to exploit lean thinking concepts in order to manage, improve and develop the product faster while improving or at least maintaining the level of performance and quality. Lean thinking concepts encompass a board range of tools and methods intended to produce bottom line results however, value stream mapping (VSM) method is used to explore the wastes, inefficiencies, non-valued added steps in a single, definable process out of complete product development process (PDP). This single step is highly complex and occurs once while the PDP lasts for 3-5 years. A case study of gas turbine product has been discussed to illustrate and justify the use of proposed framework. In order to achieve this, the following have been performed: First of all a current state map is developed using the Gemba walk. Furthermore, Subject Matter Experts (SMEs) brainstormed to explore the wastes and their root causes found during the Gemba walk and current state mapping. A future state map is also developed with removing all the wastes/inefficiencies. Besides numerous intangible benefits, it is expected that the VSM framework will help the development teams to reduce the PD lead-time by 50\%.
\end{abstract}

Keywords: Product development, lean thinking concepts, value stream mapping, gemba walk 


\section{Introduction}

Owing to the fact that products launched earlier capture the major market share achieving thus a phenomenal success (Kotler, 2003). Organizations are witnessing a scenario of maintaining or enhancing the product quality and reducing the "time-to-market" (TtM) parameters simultaneously. In order to achieve the aforesaid goals (enhancing quality and reducing TtM) for long-term success and sustainable competitive advantage, product development (PD) has continuously been emerged as an area of research for both industry and academia (Droge et al., 2000; Tyagi et al., 2013). PD has always been a challenging task and, surprisingly every organization considers it as a primary tool to surpass the competition. In general, PD aims to bring a new/enhanced product or a variant of a product(s) to the consumer. In $\mathrm{PD}$, emphasis is set on the design and development of a product aiming to achieve several key criteria such as mapping of customer requirements, quality, technology development, product strategy, cost, interface management, etc. (Clark and Fujimoto, 1991). PD comprises of a sequence of steps/activities where new/incremental product ideas are conceived, investigated, taken through the design process, manufactured, marketed and supported through aftermarket services (see Fig. 1). This whole process which starts from market research to delivery is termed as the product development process (PDP). Each organization adapts the structure of PDP to suit their specific needs and capabilities from one product to another. PDP typically follows a framework defined in a sequence of review phases (such as design and gates) to assure the implementation of a structured project management process.

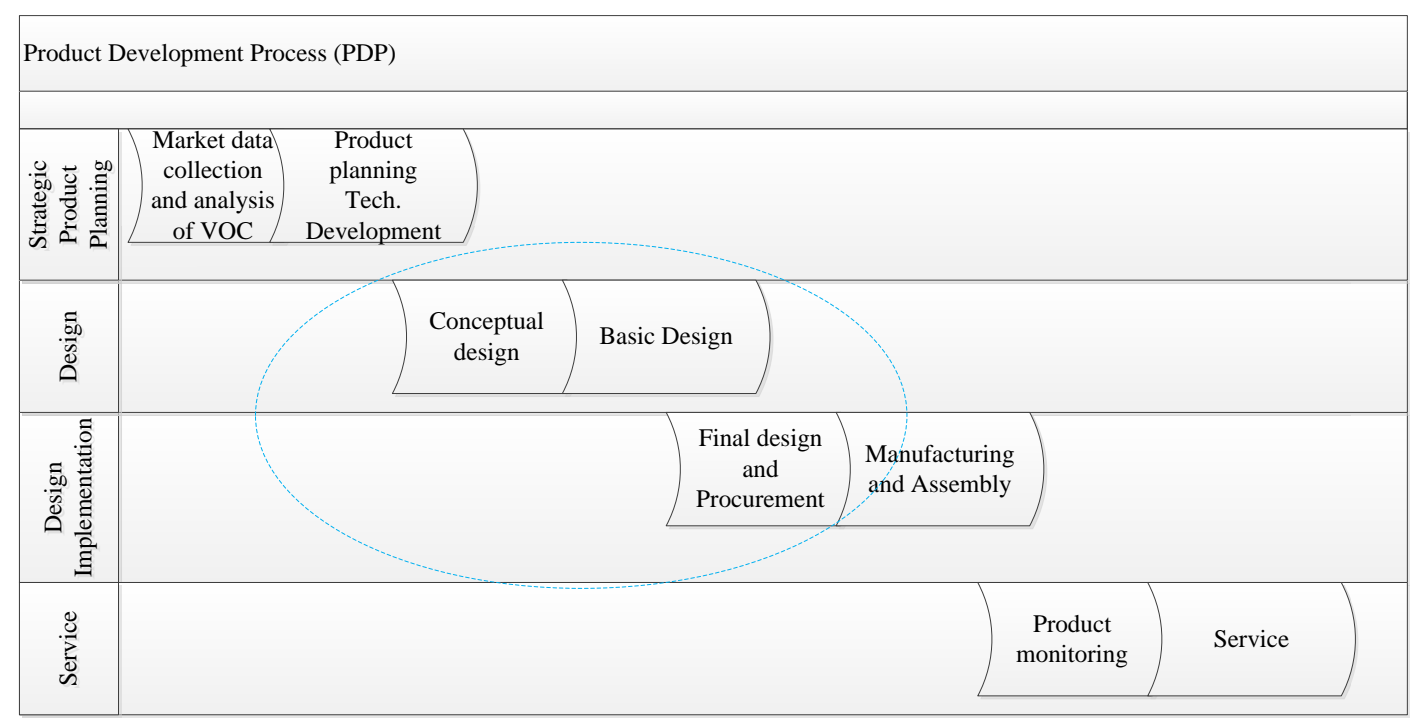

Fig. 1. Stages involved in a product development process 
In order to be sustainable and competitive, an organization has to effectively improve the TtM parameter. In this context, lean thinking concepts have gained a lot of attention in the past decade in terms of identifying and removing wastes from manufacturing and many service industries (Kennedy, 2003; Morgan and Liker, 2006). Particularly, the implementation of lean thinking concepts in manufacturing has turned out to be a more enduring advancement of earlier research works (Khalil \& Stockton 2010). McManus (2005) stated that a tested theory that puts lean thinking into the heart of a holistic system and has the ability to extend across other elements of an enterprise, such as product development, is still rarely mentioned in the literature. This is owing to the inherent differences between manufacturing and product development, and so it is worthwhile to compare the two to notice the distinctions (see Table 1). For example, in the former, loopbacks are associated with wastes and considered to be a diminishing contribution, however in the latter, loopbacks could be associated with gaining important dynamic knowledge. Hence, direct implementation of lean principles from manufacturing to product development is questionable and full of doubts (Radeka, 2012). Therefore, lean thinking concepts need apposite modifications to work well in a PD environment. Studies focusing on tools based on lean thinking concepts which are particularly designed to implement in PD from a pragmatic view are currently lacking and so an immediate attention is required. Practitioners are still experimenting by following the philosophy "learning by doing" to see what works and what does not as implementation guidelines have not been laid down yet. Moreover, the related works only offer trivial discussion and guidance to implement lean thinking concepts such as value stream mapping in PD but exhaustive results and analysis are not found. Extensive literature review conducted in this research domain (see section 2) clearly indicated that very limited work has been done in the area of lean applications in PDP and therefore a research gap exists.

Keeping the aforesaid facts in mind, this research attempts to bridge this shortcoming and research gap by presenting a qualitative framework and illustrating its application. The proposed framework focuses on the practical implementation of lean thinking concepts while aiming to identify and eliminate the non-valued added steps (wastes) in a PDP to minimize the lead-time. The wastes are mainly explored by drawing a value stream map of as-is state using the Gemba walk. The "as-is" map assists in capturing the snapshots of how things are currently done and areas of potential improvements. Future state map is also developed by incorporating all the proposed improvement ideas. One of the ultimate aims of this research is to help the chosen 
company $\mathrm{ABC}$ in their long term goal to meet the PD lead-time requirements of product $\mathrm{X}$ at generation $\mathrm{Y}$ to achieve a competitive advantage among its competitors.

\section{Table 1}

Inherent differences between manufacturing and engineering in terms of lean principles (McManus, 2005)

\begin{tabular}{|l|l|l|}
\hline Lean Principle & Manufacturing/production & \multicolumn{1}{c|}{ Engineering } \\
\hline Value & Visible at each step, defined goal & Harder to see, emergent goals \\
\hline Value stream & Parts and material & Information and knowledge \\
\hline Flow & Iterations are waste & Planned iterations must be efficient \\
\hline Pull & Driven by takt time & Driven by needs of enterprise \\
\hline Perfection & Process repeatable without errors & Enables enterprise improvement \\
\hline
\end{tabular}

The scope of this paper lies within a single and definable process extracted from a complete PDP. Based on past experience of SMEs, on a selected process segment Pareto chart analysis and brainstorming were conducted. In addition, a detailed discussion was done among SMEs before selecting the process unit which needs immediate attention and that has high potential for improvement. The selected part of PDP plays an important role in deciding the PD lead-time, and thus ensures timely delivery of the product to the customers. It also involves the higher number of human resources as it requires participation of multiple departments from the business network. Moreover, a larger number of iterations are required at additional cost and time to attain a certain level of quality and maturity in the execution. Rework without proper sequencing during steps execution affects the final product quality. It requires the downstream partners to wait causing further delays, affecting the PD lead-time. Therefore, the performance of other departments highly depends on this portion of PDP. Based on the aforesaid reasons, the authors also believe that here lies the highest potential for improvement. A manufacturing-based PD processes for Gas Turbine (GT) products are primarily considered in this research. Such processes generally consist of the activities that: (a) determine whether a new product is required to serve some needs (b) conceive a concept for that product based on customer's requirements identified after a complete market analysis (c) develop all the technical specifications (d) validate both design and production (Yang, 2007). These products have general characteristics such as a complex module structure, a long development cycle time, a long lead time in production, and 
high costs in parts; whereas these processes are characterized as highly complex to organize and manage.

The remainder of this paper is organized as follows: the next section reviews the relevant literature related to PDP, lean thinking concepts application in manufacturing and engineering. A brief summary of product and company background is provided in section 3. Section 4 details the implementation procedure of lean thinking concepts (VSM) as a strategic decision making tool for the underlying problem. The details of current state analysis to develop future state are provided in section 5. Section 6 highlights the expected benefits after implementation of proposed model from the managerial perspective and finally section 7 summarizes the entire paper and provides the direction for future research.

\section{Literature Review}

Product development (PD) is not a modern area of concern rather it has been an area of active research for decades (Imai et al., 1985; Wheelwright and Clark, 1992; Fleischer and Liker, 1997; Langerak and Hultink, 2005; Tyagi et al., 2013). PD performance is basically accessed in terms of three key criteria, namely: quality, cost, and lead time. In simple terms, the prerequisites to sustain successfully in tough competitive marketplace in $21^{\text {st }}$ century are higher product quality, lower cost and on-time customer delivery (Roemer et al., 2000). PD is among the most utilized research domain to improve PDP with a view to achieve the aforesaid goals (Barczak and Kahn, 2012; Cankurtaran et al., 2013; Agarda and Bassetto, 2013). An efficient PDP is simply an enabler of better products with improved quality at cheaper cost. However, a number

of obstacles prevent PDP from being under control and well managed. These obstacles have plagued many companies for years.

To tackle these obstacles, the authors investigated many models of PDP in the literature (Clark and Fujimoto, 1991; Wheelwright and Clark, 1992; Anderson and Pine, 1997; Ulrich and Eppinger, 2000). Clark and Fujimoto’s (1991) PDP contains four major development phases: concept generation, product planning, product engineering, and process engineering. Wheelright and Clark (1992) merged the last two phases (product and process engineering) of Clark, and Fujimoto's (1991) model into one phase and introduced a new fourth phase named pilot production/ramp-up. Anderson and Pine (1997) proposed a recommendation of minimum five phases in a development model whereas, Ulrich and Eppinger's (2000) generic model contains 
exactly five phases: concept generation, system level design, detail design, testing and refinement, and production ramp-up. All the aforementioned models cover the PDP at most upto production/ ramp-up but they do not consider the service phase. Service is one of the critical phases for certain products, such as Gas Turbine (GT), airplane, and car since it could last over two decades. Approximately 80\% of business profit comes from this phase (Cai et al., 2011). In GT service stage typically a designer continuously works on upgrading design of parts or modules of a gas turbine, based on the feedback of performance about current product(s). An advanced PDP model extended to include service phase proposed by Cusumano et al., (2012) is adopted in this research (see Fig. 1). This research considered the vital phases of PDP such as conceptual design, detailed design, review and validation among all process steps. Surely, Lean Thinking (LT) concepts extended on PDP not only help the front end users who collect the consumer needs, brainstorm, and develop concepts but also provide input to the back end where transition from design to production occurs. However, in this study the special needs of these phases are not targeted. Clearly, they can get benefits from lean analysis in future endeavors.

As mentioned earlier, an organization has to effectively improve the time-to-market (TtM) parameter to remain competitive. The greatest reduction in TtM occurs when an organization streamlines its processing stages, undertakes activities in parallel, and proactively launches the product in the market (Towner, 1994). In regards to streamlining processes, Toyota Production System (TPS) has gained a lot of attention from manufacturing and from many service organizations (Smith and Reinertsen, 1998; Kennedy, 2003; Morgan and Liker, 2006). TPS mainly assists in identifying and removing wastes embedded into process, product design, and policies without offering any value (Kennedy, 2003). TPS or lean thinking thus emerged as an effective and efficient way to continuously decrease costs and improve profits by utilizing the minimum required level of essential attributes like time, space, machine, equipment, and energy to produce a product or to provide a service. The value of a product also increases when wastes pertaining to transportation, inventory, waiting, overproduction, over-processing, defects, and rework are eliminated (Sullivan et al., 2002). It is evident in literature that effective application of lean thinking concepts is a powerful enabler of performance improvement though their application is not a strategy themselves.

The lean thinking (LT) term was first coined by Womack et al., (1990) in his book "The Machine That Changed the World." It refers to the fundamental concept of the waste 
minimization by questioning the basic understanding of business and manufacturing. Womack and Jones (2003) proposed the five lean principles which are: (1) specify value, (2) identify the value stream and eliminate waste, (3) make the value flow, (4) let the customer pull (value), and (5) pursue perfection. They have emphasized that the term "lean" mainly depends on one critical starting point called "value." Value can be defined only by the customer, and it can measure the manufacturer's efficiency when the product is delivered at a reasonable price at an appropriate time in the right amounts. The term lean thinking is also compatible with many other manufacturing techniques, such as Agile Manufacturing, Just-in-Time Manufacturing, Synchronous Manufacturing, World-Class Manufacturing, and Continuous Flow (Kumar et al., 2006). Russell and Taylor (1999) mentioned many lean tools like one piece flow, VSM, poke yoke, standard work Kaizen, and visual control to minimize the waste in manufacturing. In addition to manufacturing (Panizzolo, 1998; Seth and Gupta, 2005; Herron and Braiden, 2006; Worley and Doolen, 2006; Demeter and Matyusz, 2011), many other sectors such as software development (Poppendieck and Poppendieck, 2007), project management (Ballard and Howell, 2003), healthcare (Bamford and Lodge, 2007), supply chain management (Cudney and Elrod, 2010), energy management (Quinn, 2012), environmental management (Yang et al., 2011), semiprocess industry(Pool et al., 2011), food industry (Simons and Taylor, 2007), shipbuilding (Storch and Lim, 1999), aerospace (Houlahan, 1994), public services (Radnor and Boaden, 2008) etc. also have been benefited by lean thinking concepts and tools. Abdullah (2003) demonstrated VSM and lean manufacturing application in process industry specifically in steel industry. Among many lean thinking tools and methods, VSM has been very successful in pinpointing the wastes and improving the processes due to revealing nature of used metrics and flow. The main goal of developing VSM tool was to explore the interdependencies of two separate departments and tackle the situation where conventional industrial engineering tools to capture the holistic view were negatively found (Seth and Gupta, 2005; Singh et al. 2011).

According to the literature, on an average, it takes around 4-5 years to develop a new product (gas turbine) while about $50 \%$ of costs incurred tend to be spent on wastes (Anand and Kodali, 2008). A plethora of research in the literature proposed methods to reduce PDP lead time and wastes (Millson et al., 1992; Maylor, 1997; Droge et al., 2000; Langerak and Hultink, 2005; Tyagi et al., 2011; Cai et al., 2011; Tyagi et al., 2013). Some successful and efficient methods, tools and techniques were brought up concerning different issues pertaining to PDP (Syan and 
Menon, 1994; Voss et al., 1995; Zhang and Yu, 1997; Zussman and Zhou, 1999; Tyagi et al., 2012). However, no general solution exists in an organization to solve complex problems. An ambiguity on how to select best suited tool(s) for improving PDP still prevails. As discussed above, Lean thinking has been successfully implemented in manufacturing environment (Seth and Gupta, 2005; Worley and Doolen, 2006; Kumar et al., 2006) and also has a huge potential to reduce TtM factor in PD. However, there are many distinct differences between PDP and manufacturing process, so lean principles have to be modified to work well. The already proven best tools such as VSM have to be further scrutinized, studied, customized, and integrated into PDP. Undoubtedly, there are many lean tools which are being developed and implemented or are in the implementation phase. Nonetheless, after a detailed discussion with the working group on PDP, the output was a consensus on adopting VSM to help guarantee success in improving PDP.

\section{LeanPPD}

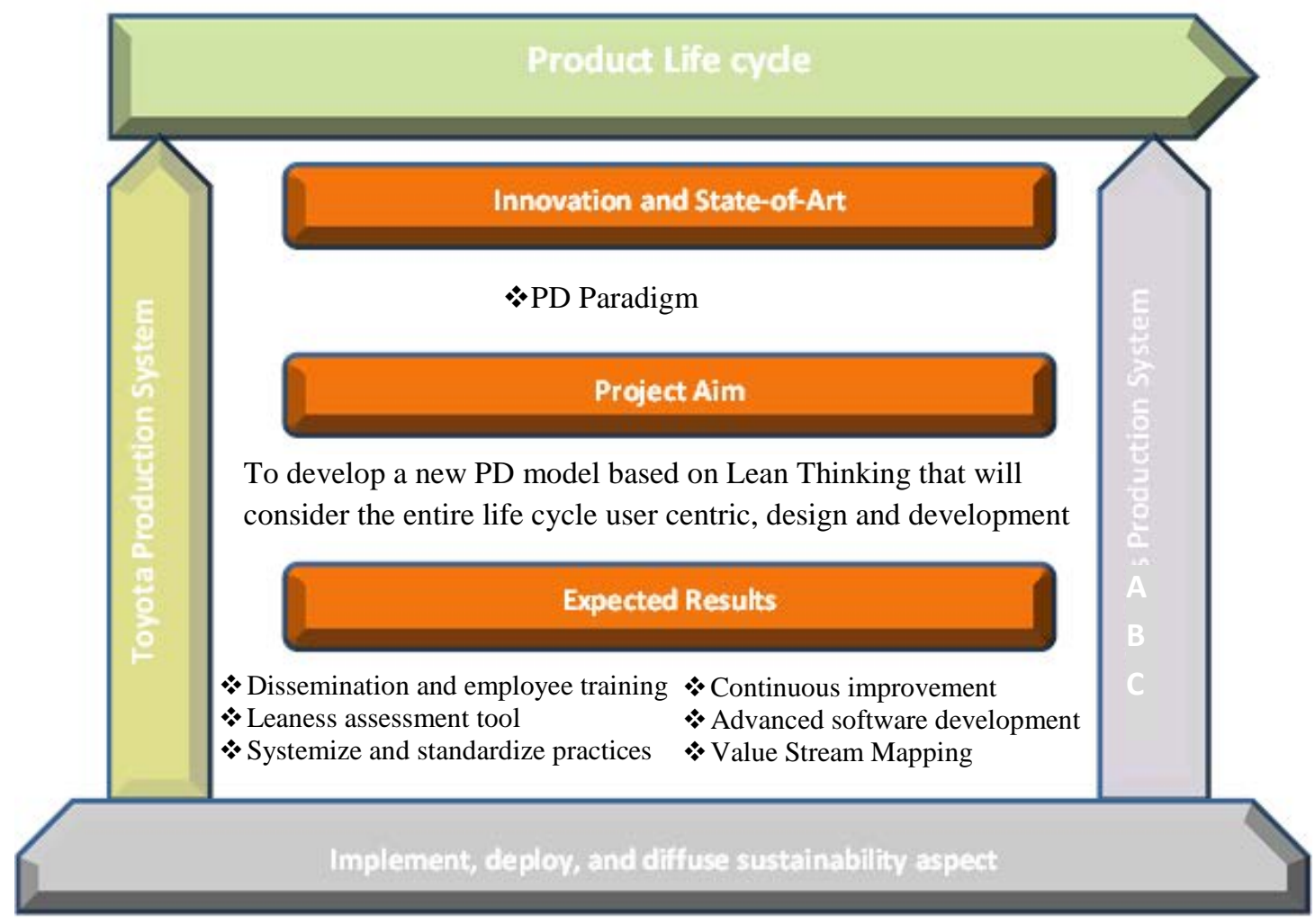

Fig. 2. Summary of PD model (Shehab et al., 2010) 
Techniques such as concurrent engineering (Tyagi et al., 2013), total quality management (Voss et al., 1995) etc. have been implemented and quite successfully improved the performance of PDP. However, there is still a shortfall in the expected or desired advancement to take PD to the next level (Worley and Doolen, 2006). Such shortfall is believed to be bridged through the implementation of lean thinking concepts namely VSM. It is evident from the literature review that except McManus (2005) not much emphasis has been laid on LT concept implementation in the PD environment. Thus, the main objective of this research is to report preliminary approaches and expected results of our contribution towards a systematic and formal lean implementation. In this regard, the major focus is on VSM among lean tools as it is one of the most important concepts implemented successfully in various sectors. VSM framework contains a large number of principles and methods in its structure. The authors outline a comprehensive strategy that combines many lean tools, and several sound principles (see Fig. 2) (Haque and James-moore, 2004; Huthwaite, 2004). VSM is mainly used to identify the potential areas for improvement by exploring and removing the wastes in a PDP, while other tools are used to conduct analysis. The goal here is to implement lean tools beyond just the identification and reduction of waste, but to support value creation of sustainable products and foster quality. In the next section a generic framework of VSM implementation that addresses most of the concerned issues is proposed.

\section{ABC company background and business}

The unit under this research study is a part of a large organization (ABC) which is stretched into diversified areas including healthcare, energy, consumer products, construction, and financial products, etc. This unit is a branch of the energy sector established in early period of $20^{\text {th }}$ century and currently has more than 200,000 employees in more than 100 countries. This company develops and produces a wide range of gas turbines (GT) classified on the basis of maximum output (A MW to B MW) to fulfill the diversified demands of customers based on their needs. It is a leader in developing, producing and supplying GT products and presently covers a market share of more than $40 \%$. In the earlier phase of last decade, GT accounted only for $15 \%$ of the power generation industry. The current demand of GT products has witnessed a significant increase soaring upto $40 \%$ by the next two decades according to a data published by Department of Energy (DOE). It is required to increase the annual GT production by more than 
2.5-3\% to match the demand worldwide. This scenario is putting a huge amount of pressure for efficient PD to avoid any threat from the competitors regarding cheaper and faster products. The PD time for GT variant $\mathrm{X}$ is 4-5 years. The company further wants to reduce it to beat the competitors and to gain a larger market share. In order to achieve these objectives, companies have already started to critically explore, develop, customize, and modify various tools and methods that fall under the category of TPS. Keeping this in mind, company ABC wants to use VSM to explore the wastes in PDP and eliminate them. The next section will present the current state map and future state map for a manageable portion of PDP.

\section{Value stream mapping to develop "as-is" state}

The advent of value stream mapping (VSM) has replaced conventional recording approaches from an analysis perspective. This is due to the fact that VSM provides a visual platform to capture the input/output of "door to door" steps, involved resource, cycle time and utilized time. As stated earlier, the five lean management principles forming the backbone of VSM are: preciously defining value for your product from customer's point of view, developing value stream and eliminate wastes; uninterrupted flow, avoiding push to customers rather letting them pull and pursue to reach the perfection level (Womack and Jones, 2003). Based on lean thinking principles, the tasks performed in PDP can be classified into the following 3 categories: 1) Value added: This category of tasks are the ones that really move product design forward and create values that external customers are willing to pay in order to get their job done; 2) Non value added but necessary: This category of tasks are the ones that may not move the product design forward and may not create values that external customers are willing to pay, but they are necessary under current circumstances; 3) Waste: This category of tasks are the ones that does not move the product design forward and they have no value for external customers. These tasks should be identified and eliminated.

Mascitelli (2007) stressed the importance of increasing the ratio of value-added time, and to decreasing the ratio of non-value added but necessary and the waste. Mascitelli stated that based on industry survey, in an 8 hour working day, the average value added hour is only 1.7 hours in the Western companies. However, Toyota claimed that its average value added time is more than $50 \%$ (Womack and Jones, 2003). In order to reach that state, expectations are to find wastes

associated with the information flows in PDP analogous to the seven wastes identified in the 
factory (last waste is in addition to traditional waste). The wastes related to information flow are considered in this research because during development projects primarily the information is exchanged among cross-functional team members instead of any physical products. The seven info-wastes include (Womack and Jones, 2003):

- Overproduction: Creating too much of information

- Inventory: Having more information than you need

- Extra processing: Processing information more than required to get an indented output

- Transportation: Moving information from one place to another place

- Waiting/queuing: Waiting to process the information or waiting to get the information

- Excess motion: Moving of people to access/process the information

- Defect/rework: Error or mistakes that causes to redo the efforts to correct the problem

- Underutilized people: The employees are either not assigned or have a very limited roles. However, in reality they are more skilled and capable to handle more if the process has been responsibly designed more effectively.

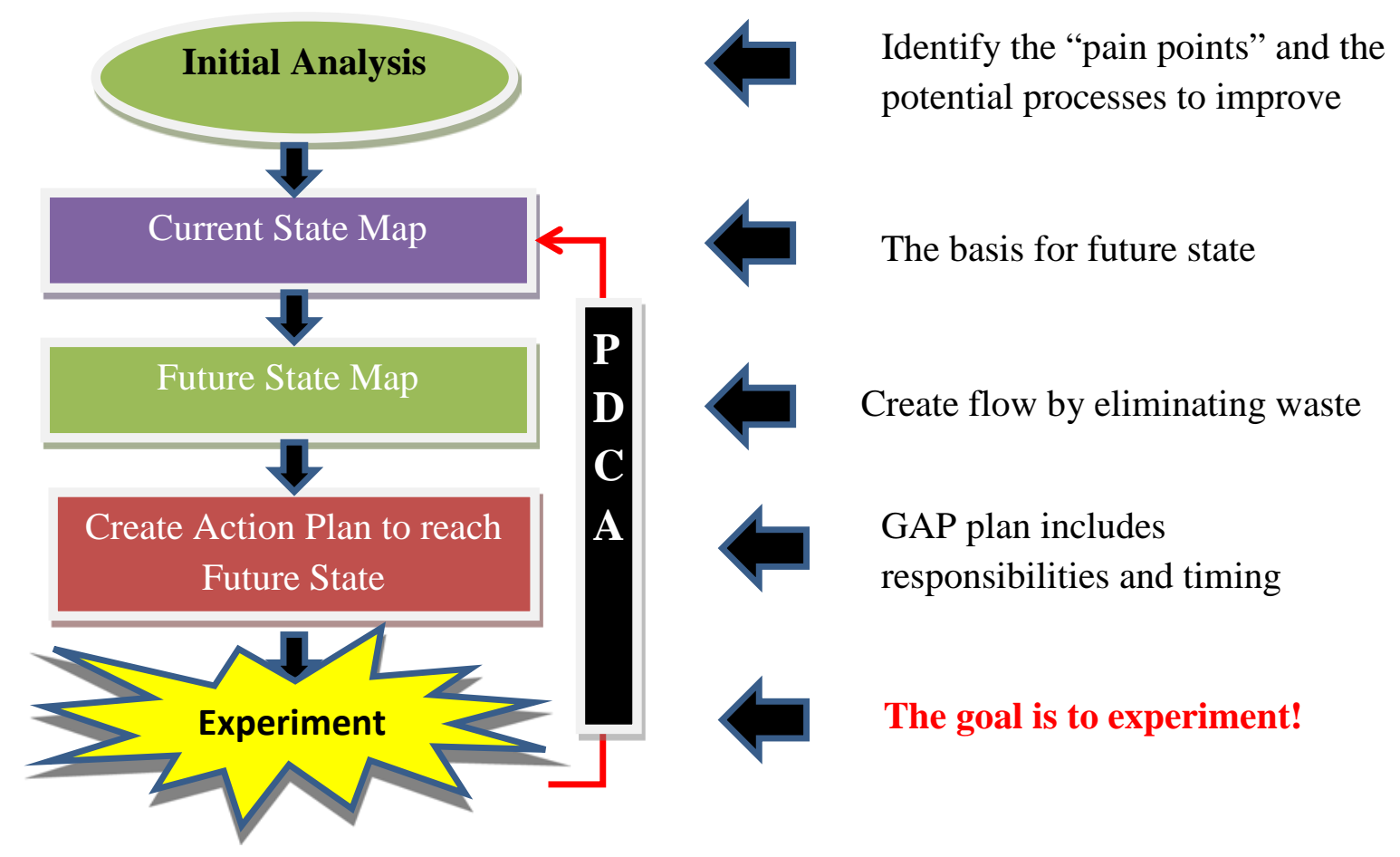

Fig. 3. VSM implementation phases and their respective objectives

Fig. 3 shows the high level steps involved in implementation of VSM and their objectives in a single but definable process out of a complete PDP are detailed in Table 2. The initial analysis (scan and plan) was conducted to identify the main pain points and select a bunch of potential 
processes for improvement. The Pareto analysis was conducted to prioritize the processes based on the total time in the systems and total cost of resulting component. In the next step, the current state is mapped with the prospect of reaching to the future state. The objective is to create an action plan to reach the future state and realize all the benefits by eliminating wastes. Some experimentation using PDCA (Plan Do Check Act) cycle are also performed to gain better results in reaching the future state. Next sub-section discusses the Gemba walk for the underlying study.

\section{Table 2}

The planning for VSM: tasks, output and their objectives

\begin{tabular}{|c|c|c|c|}
\hline Description & Tasks & Output & Objective(s) \\
\hline $\begin{array}{c}\text { Initial } \\
\text { analysis }\end{array}$ & $\begin{array}{l}\text { Review of business plan, } \\
\text { strategy, key metrics etc }\end{array}$ & $\begin{array}{c}\text { Setting the stage } \\
\text { High level picture of workspace }\end{array}$ & $\begin{array}{l}\text { Get familiarized with } \\
\text { process and business }\end{array}$ \\
\hline Process walks & $\begin{array}{l}\text { A physical walk through the } \\
\text { PD workplace noting the } \\
\text { current high-level } \\
\text { organization design for flow } \\
\text { of people, information, } \\
\text { services }\end{array}$ & $\begin{array}{l}\text { A picture of organization } \\
\text { identifying high level flows and } \\
\text { the waste associated with the } \\
\text { current PD design, including the } \\
\text { review of appropriate documents }\end{array}$ & $\begin{array}{c}\text { To collect the finite possible } \\
\text { processes in detail. }\end{array}$ \\
\hline $\begin{array}{c}\text { Process } \\
\text { Quantity } \\
\text { Analysis } \\
\text { (PQA) }\end{array}$ & $\begin{array}{l}\text { Breakdown P.D. services into } \\
\text { "families" which have the } \\
\text { same process steps and } \\
\text { similar process times. } \\
\text { Determine various process } \\
\text { cells required to deliver the } \\
\text { best value proposition } \\
\text { Define natural sequencing of } \\
\text { activities }\end{array}$ & $\begin{array}{l}\text { A matrix of the current mix of } \\
\text { PD processes } \\
\text { Potential product family solutions } \\
\text { based on common routings } \\
\text { (sequencing \& time) } \\
\text { Consider potential flow } \\
\text { improvements to processes }\end{array}$ & $\begin{array}{l}\text { The objective is to select } \\
\text { vital few from trivial many } \\
\text { processes to focus on } \\
\text { important. Pareto analysis } \\
\text { can be helpful. }\end{array}$ \\
\hline Process walks & $\begin{array}{l}\text { Review deeper levels of the } \\
\text { process in the Gemba to } \\
\text { confirm initial improvement } \\
\text { ideas }\end{array}$ & $\begin{array}{l}\text { Achieve better understanding of } \\
\text { the potential improvements for } \\
\text { the VSM }\end{array}$ & $\begin{array}{l}\text { Break down the vital few } \\
\text { into small steps to find the } \\
\text { root cause of problem and } \\
\text { find wastes. } \\
\text { Important tools are: Brain } \\
\text { storming, Fishbone diagram, } \\
\text { Fault tree analysis, } 5 \text { Why's, } \\
\text { Failure Modes and Effects } \\
\text { Analysis, Pareto chart }\end{array}$ \\
\hline Action plan & $\begin{array}{l}\text { Determine action plan for } \\
\text { VSM workshop }\end{array}$ & $\begin{array}{l}\text { Finalize action plan including } \\
\text { next steps, resources and timing } \\
\text { for VSM workshop }\end{array}$ & $\begin{array}{l}\text { Make a plan to solve root } \\
\text { causes of problems \& } \\
\text { remove waste to reduce } \\
\text { lead-time } \& \text { improve quality } \\
\text { at cheaper cost. }\end{array}$ \\
\hline
\end{tabular}




\subsection{Pareto diagram}

Pareto diagrams are very specialized forms of column graphs. They are used to analyze a problem from a new perspective, focus attention on problems in priority order, compare data changes during different time periods, and provide a basis for the construction of a cumulative line. They are predominantly used for prioritization purposes after identifying major problems (or opportunities) and ranking them. They can help teams get a clear picture of where the greatest contribution can be made. For the underlying problem, a list of component was selected and corresponding time in system and total cost was calculated (see Fig. 4).

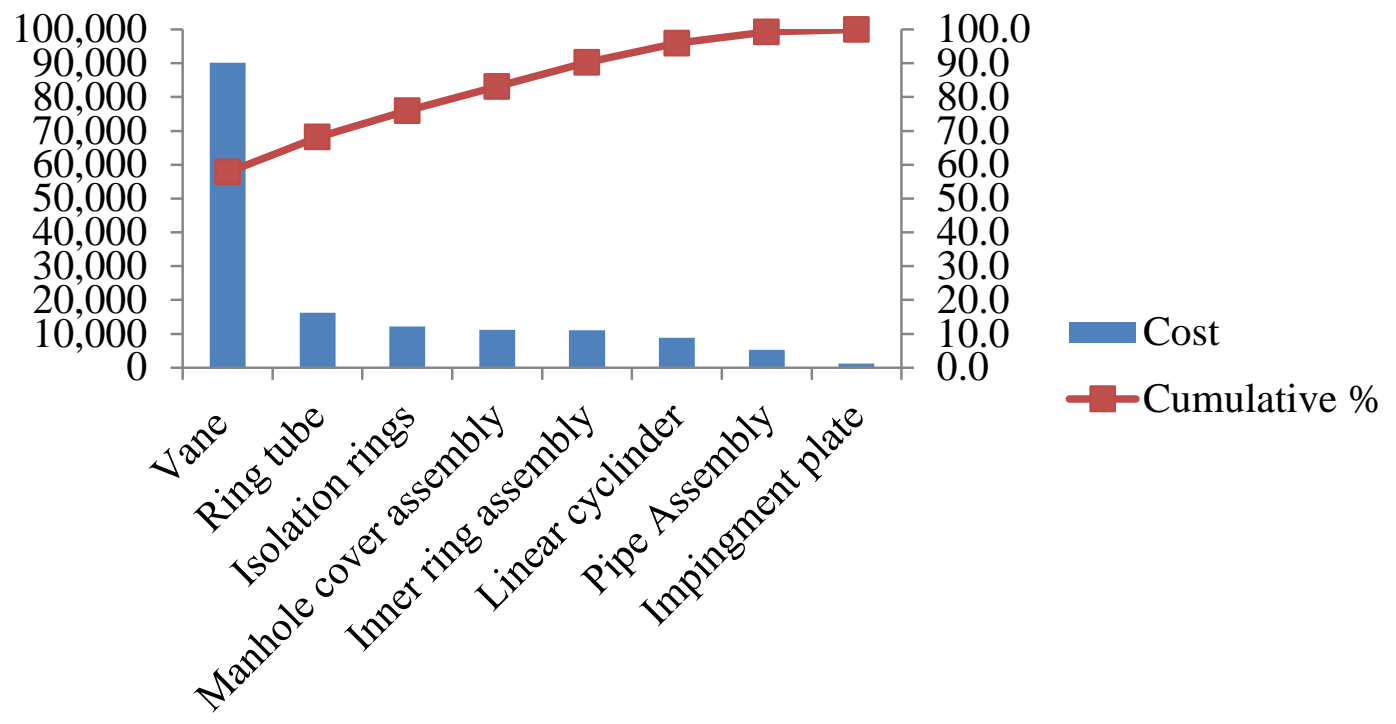

Fig. 4. Pareto analysis to select the underlying process

From the Fig. 4, it is evident that vane components are constitute around $70 \%$ of the total cost and hence are the focus of this research.

\subsection{Gemba walk for scan and plan}

Gemba refers "the real place" where the actual action is executed. The effective use of Gemba encourages the "go-see” principle. It means getting out of office and walking the process with concerned people, to help them discover issues and fix them. It became a mechanism for “catching” people doing the right things and getting recognized for it. Gemba walk has two fold advantages. First, it is a powerful way to support continuous improvement and process standardization with the help of company leaders, managers and supervisors. Such practice of being in continuous touch with team players helps in keeping an eye on real development issues 
in business and in resolving them as soon as they surface. It helps building relationships with team leaders by getting to know teammates better and helping them improve the processes. Secondly, alignment of efforts of all team members is ensured. This is fundamental to improve the effectiveness of people and to discover opportunities for improvement by asking questions and listening to the answers. When an interest is shown by senior leaders, the team is encouraged and thus performance is improved. Moreover, it improves morale by actively showing respect for people visibility and concern about how things are being implemented.

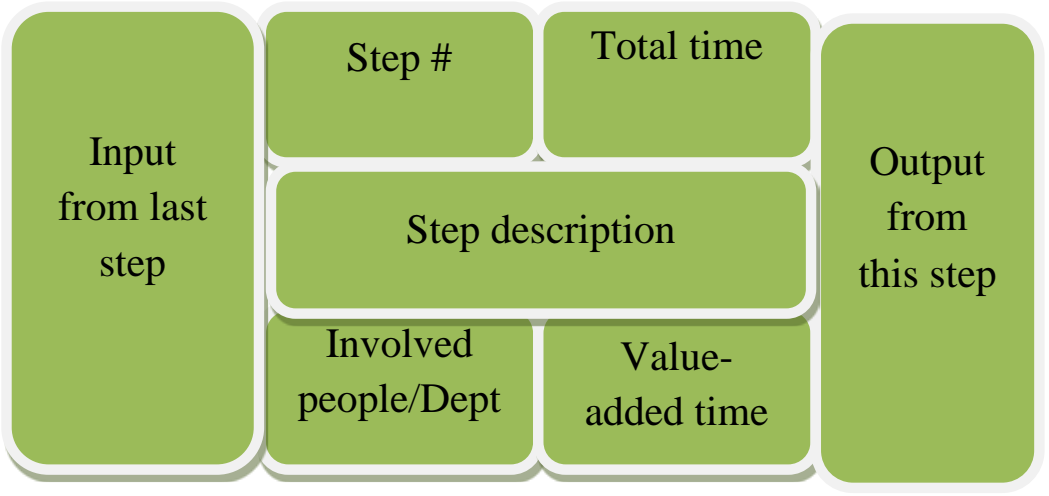

Fig. 5. Template to collect the data during Gemba walks

For this particular problem, SMEs from the involved departments as representatives were invited for a three days long workshop. These experts were gathered in a large room and were asked to provide their feedback about the current process without any hesitation. Such freedom was really necessary to get to the bottom of the basic problem. Further, all the issues were noted down and were categorized using Affinity Diagrams. The affinity diagram is widely exploited during the planning stages of a problem to organize information. It links the generated ideas and gathered facts in an organized way to form the thoughts pattern, similar to the mind mapping techniques. After a dialogue within the team and with the management support, these issues were screened to a manageable list. Since all these people were from a different department their knowledge about VSM concepts were at different levels. Therefore, to keep all the participants on the same page, lean and VSM fundamentals were introduced to everyone. In this presentation, the philosophy and basics behind VSM were explained. Keeping these basic facts in mind, the team did the Gemba walk and each team member was assigned with a particular role such as scribe, process guide, waste identifier, etc. Each member was also assigned with a very specific template according to their role. Such templates were developed in advance with the help of people who have an experience in lean/VSM. Three Gemba walks series conducted during this 
endeavor. These walks gradually moved down to the specific processes which were the target for improvement.

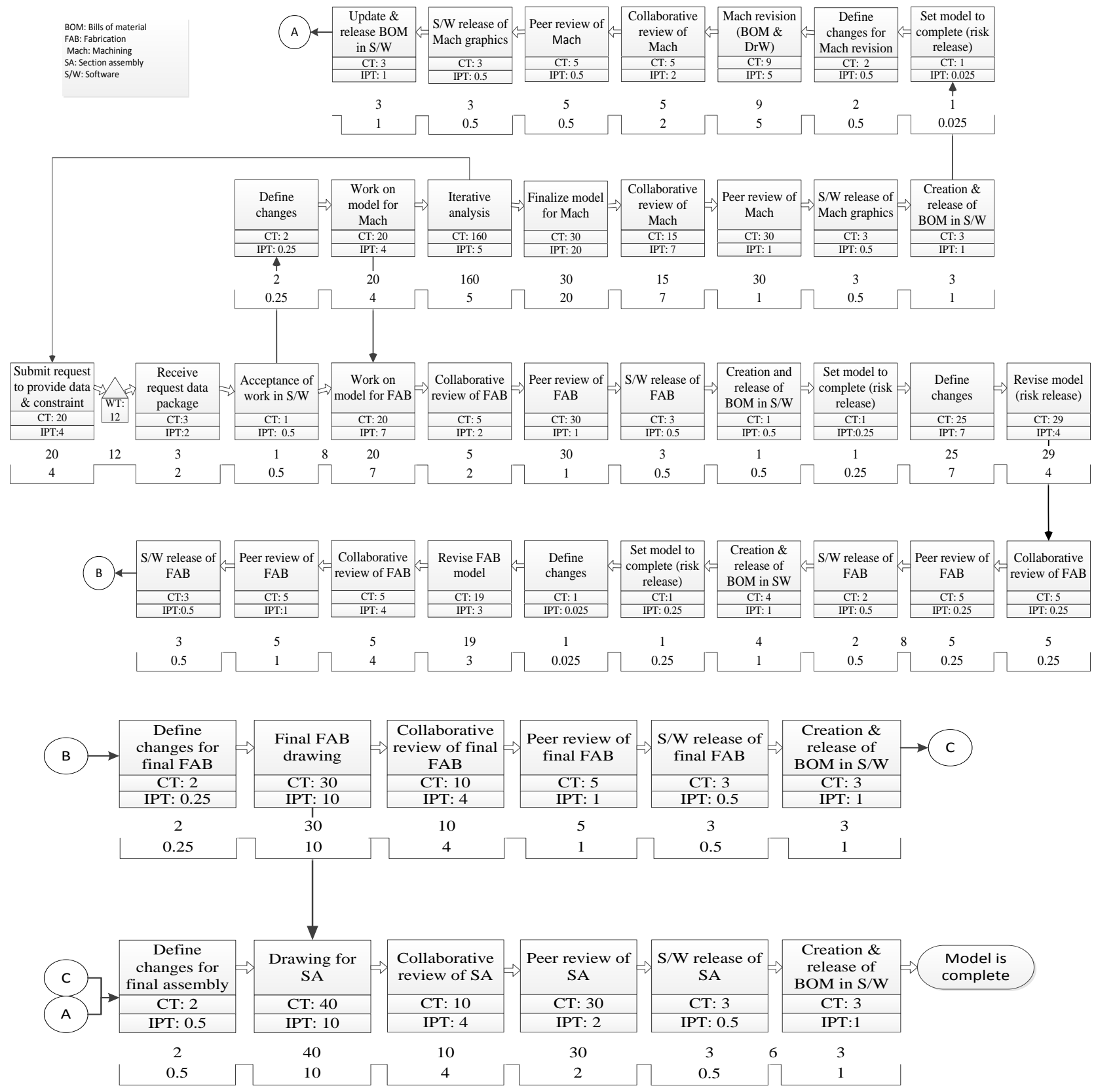

Fig. 6. Current State Map for targeted process and associated data (Modified)

\subsection{Current State Map}

Once the Gemba walk was completed, all the team members again gathered in the same room and discussed about the steps identified and written down on templates. These steps were further noted down on a sticky note and put on a large white sheet of paper on the wall. The advantage 
of using sticky notes was the freedom to change the order in case there were any updates. In order to complete one step, seven sticky notes of different colors were used as shown in Fig. 5. This figure shows the template used to select the data during Gemba walk. Here the first box shows the input information from the previous step which can be in form of action items or documents. The next box is the step number in the Gemba walk. The involved people or department is listed in a box just below it. The next two boxes contain the information about total time taken to execute the step and what amount of time is value added. In between these two boxes, there is a box that has step description. This step has the brief description of conducted action items. Since in the development process it is difficult to capture the exact information about value-added and waste related data, these values are thus approximated. These values are best available values in the mind of person who actually does the real work. Due to confidentiality reason, the data has been modified according to a certain rule. The data for current state is summarized in the following Table 3.

For the problem at hand, the sticky notes were used in order to collect all the issues in an organized way. Every issue was discussed and written down on the sticky note and posted on the chart paper. For visualization purposes, standard icons are used to follow the information flow instead of physical materials to achieve operational excellence by brining all the problems to the surface. A current state map - basically a high-level description of a business process- is developed with a view to have deep insights into the present situation of product X (see Fig. 6). It offers a clear outlook on current process so that opportunities for improvement can be explored by revealing and visualizing problems. The figure 6 evidently reflects the process steps and their various attributes like waiting time, total time taken to execute a step, value added time, involvement of different department and information flow. The figure provides a holistic view of process steps which are not viable, for example; uncertainties or interdependencies in iterative flows that may be beneficial to create value in overall enterprise efforts. It also helps in visualizing the effects of experimentation on the as-is state in attempting to incorporate the improvement ideas. This experimentation provides a roadmap and guidance for the future state by filling up the gap areas and eliminating all obstacles that prevents flow from pragmatic view. Although it seems simple, the real challenge lies in identifying and defining what wastes are, in finding the reasons for filling information gaps and in overcoming those gaps to reach to the future state. 


\section{Analysis of current state to develop future state}

Qualitative research has been widely used in the business and organizational studies. The qualitative data are usually obtained through face-to-face interviews, observation, and documentation (Barczak and Kahn, 2012). It is considered to be particularly useful in understanding complex environments such as PDP containing "many contextual contingencies, variations, and interactive issues.” A PDP is a complex, and expensive process. It takes longer to finish due to many last-minute surprises and delay in the product development cycle targets and engineering deliverables (parts list, structured bills, routings, drawings, visual aids, or material specs). This paper attempts to discuss both problems and solutions in a PDP from a pragmatic point of view. All the research conducted in this paper is done by a member of a group who has been directly involved in the PDP. However, to maintain the confidentiality, the problems and solution approach have been intertwined with pragmatic and theoretical concepts as well as data sets, and the obtained results have been modified. During the six months research study through observation, analysis, team meetings, and discussion with other stakeholders, many obstacles and problems have been identified in the working philosophy and protocols. However, main obstacles associated with PDP that prevent from achieving desired targets are: (1) failure to assess/identify customer needs accurately in timely manner; (2) lack of good internal communication and control; (3) absence of a formal PDP implementation and new tools; (4) lack of early customer/supplier involvement in the PDP; (5) lack of skilled staff training and development; failure to recognize PDP as a total company activity, rather as a functional project; (6) issues associated with PD are not communicated effectively outside the engineering organization; (7) failure to identify and manage design risk; (8) too many systems usage; (9) lack of standardized processes; (10) requirements of excessive reviews and verification; (11) change in priorities or requirements causing rework towards the end and many more unaccounted elements. 


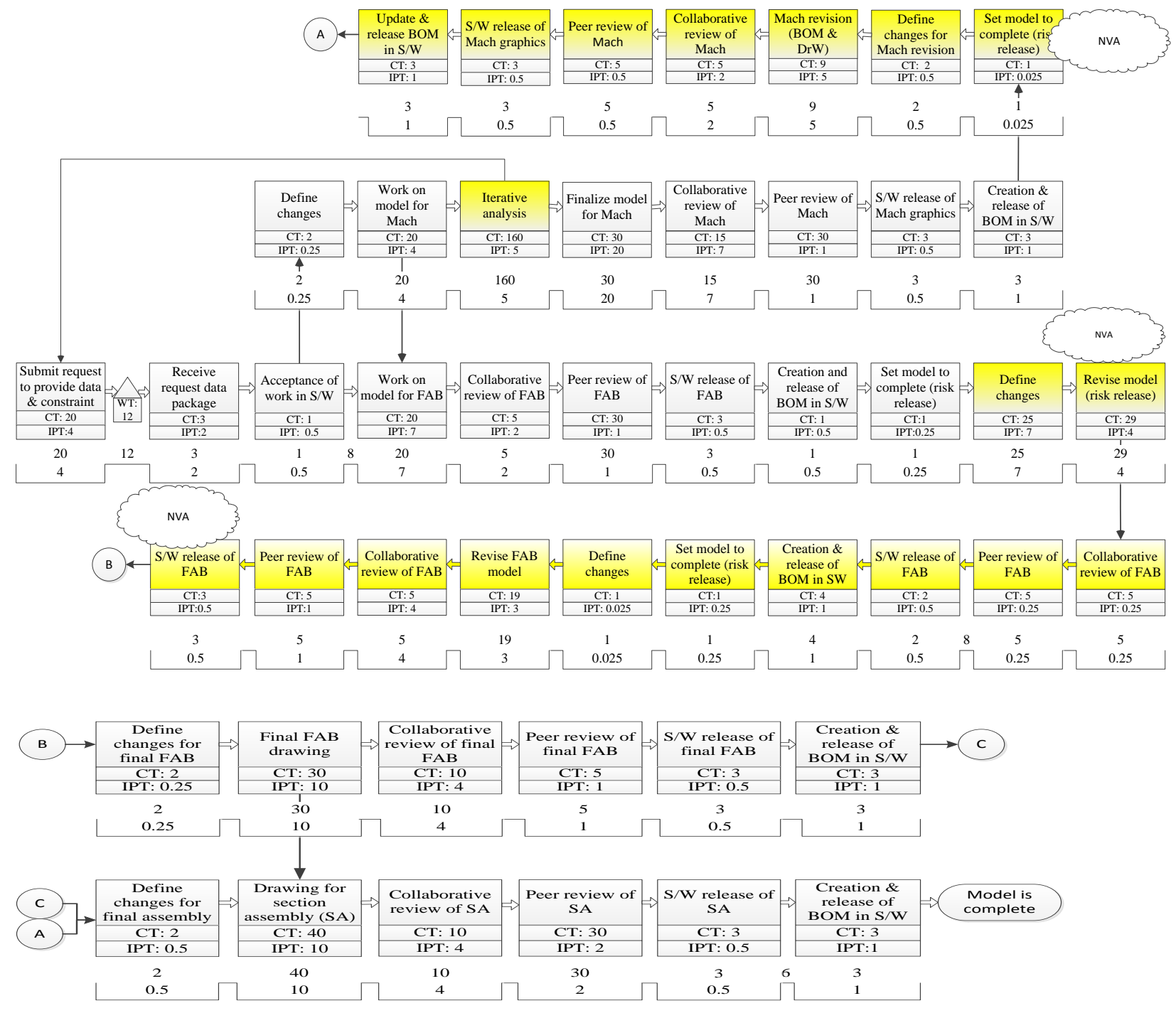

Fig. 7. Analysis of current state map (Modified)

A few assumptions are made for the analysis purposes only that are as follows: 1) most of the obtained data is collected from the user's computer. Rest of the data is collected during interview based on the memory of the power user which may not exactly reflect the associated values. 2) Affects due to variation of data are not considered in this study. The data for the product variant $\mathrm{X}$ at generation $\mathrm{Y}$ could be different for the other variant(s) of the same product family. However, it is assumed that data remains the same for next generation of the product even though it will have few fundamental changes in the design and configuration. The information for various selected criteria to measure the performance of current estate map of for target part of the process is shown in Table 3. This information comes from the current state or "as-is" state shown in Fig. 6. Total number of steps involved in current state map is 48, out of 
which only 10 steps are completely value added (20\%). As shown in figure 6, total time in system or lead time is 620 days while cycle time or actual processing time which adds value is only 122.55 days. Most of time is spent on waiting for information, decision or processing over information or duplicate information, rework due to early release of information. Total amount of waiting time is thus 272 days which is mainly caused by 72 required hands-off due to crossfunctional team involvement. Moreover, the right people from the cross-functional teams were not involved from the beginning of the project. The project is sent back by a month at every instance when new members from cross-functional team join. This time mainly goes into bringing them upto speed about the current status of this project. Additionally, their input also requires conducting rework, thereby augmenting the lead time. Another major reason for the waiting time is due to the fact that engineer's roles/responsibilities were not clearly defined in the beginning. This makes no one to take ownership for the work required and causes delay.

Additionally, there are 17 iterations of different steps that constitute for 160 days of the total development time. The reason for the iterations is that deliverables are not clear upfront and engineers were lost in using hit and trial method to reach the final state. This situation is further marred by absence of no knowledge base which can be used as a start point and design can be built on top of that. Decision-making was slow and required multiple design reviews, validation and approvals by personals from the senior manager. It was difficult to get approvals on paper since most of the time those personals were on travel or tied up with other duties. The information is duplicated and released into different software's which is a pure waste and can be eliminated easily in future state. In Fig. 7, the yellow box shows the step which is waste but which may be required afterall. From the figure, it is clear that this process involves a large number of non-value added steps. In the future state, numerous non-value added steps are deleted or modified to reduce the PD lead-time. Subsequently, future state is shown in Fig. 8 and the corresponding data is shown in the Table 3 with improvements as compared to current state.

\subsection{Improvement ideas to reduce the product development lead time and future state}

Once the current state map was developed, brainstorming was conducted in the same room, to come up with ideas to reach to the future state.

\subsubsection{Brainstorming}

Brainstorming is a popular and effective tool to generate creative solutions by looking at the problem in novel ways and utilizing the diverse experience of all team members involved. It 
assists in deep diving to explore the root causes and increases the richness of ideas to obtain better solutions. It is particularly useful to break out stale and established patterns of thinking to overcome many of the issues that can make problem-solving an unsatisfactory process. It creates a positive and rewarding environment for problems solving and making it a fun task with improved bonding among team members (Baumgartner 2006). Additionally, active involvement of all the team members in developing the common solutions helps to get categorical buy in from them. Everyone was excited to provide their input.

After initial screening of brainstormed ideas, following points were listed to keep in mind to improve the current state: 1) specify deliverables explicitly at the start to conduct the right analysis at the right time. This will obviate the need of iterative analysis, reducing the frustration level of engineers. Iterations can also be reduced by quick and effective decision-making by senior managers. Of course, it is not possible to eliminate the iterations since the information is updated regularly in development projects but careful attention upfront can significantly reduce additional rework, 2) involve the right people into the project from start after clarifying their roles and responsibilities and ownership, 3) create a lessons learned portal to get immediate help in future endeavors, if required, 4) eliminate the need of duplicate efforts in releasing the information in two different systems. Basically, it was found that the development time will be reduced further when requirement of other system is removed and the power user needs to release the information only one time.

\subsubsection{Future state analysis}

Future state map demonstrates the output of the proposed changes based on the gaps identified in the snapshot of the "as-is" state of the current state. It was asked to involve the supplier earlier in the process to have a high degree of correct information and coordination. It should be achieved by improving communication upfront to foster proper information regarding product and process. This will bring the necessary knowledge to execute the steps in correct manner eliminating the need of rework through iterations at back end of the process. It will also help the involved departments to understand and share same vision for future products. 


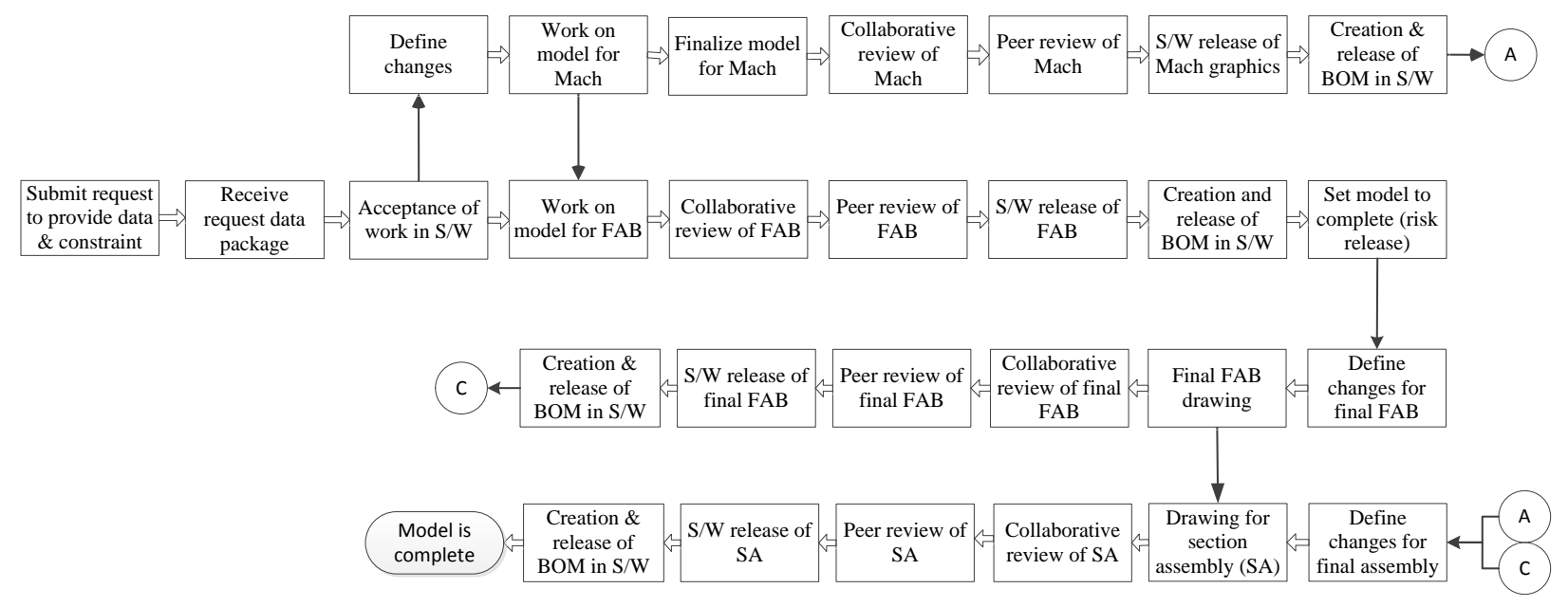

Fig. 8. Future State Map (Modified)

As can be seen from Table 3, a 30\% increment in value added steps due to removal of waste steps is achieved. The percentage of valued added time is increased from $21 \%$ to $71 \%$ (50\%). This increase is mainly due to improvement of value added steps in PDP. Waiting time is reduced from 272 days to 30 days. There is also a significant decrease in the total number of hand-offs from one department to another department for many iterations (from 87 to 23). Supplier involvement from the beginning reveals to be the main reason to reduce so many handoffs. Therefore, early involvement in the team meetings will reduce the uncertainty in the beginning of the design phase. A final decision could be reached through meetings as compared to making multiple changes later. The total number of iterations is also reduced to 8 from 17.

\section{Table 3}

Comparison of data for current state and future state and improvement

\begin{tabular}{|c|c|c|c|c|}
\hline Number & Criteria & CS values & FS values & Changes \\
\hline 1 & Total number of steps & 48 & 29 & 19 \\
\hline 2 & Number of value added steps & 10 & 15 & 5 \\
\hline 3 & Percentage of value added steps & $25 \%$ & $52 \%$ & $27 \%$ \\
\hline 4 & Total time in system & 620 days & 210 days & 410 days \\
\hline 5 & Value added time & 122.5 days & 122.5 days & 0 \\
\hline 6 & Percentage of value added time & $21 \%$ & $71 \%$ & $50 \%$ \\
\hline 7 & Total waiting time & 272 days & 30 days & 242 \\
\hline 8 & Total number of hand-offs & 87 & 23 & 64 \\
\hline 9 & Total number of iterations & 17 & 8 & 9 \\
\hline 10 & Number of software involved & 11 & 9 & 2 \\
\hline
\end{tabular}


Although, improvement ideas induced from VSM session are still in the implementation phase, there are numerous expected benefits once all the proposed ideas are implemented. Mainly, there will be a continuous focus on elimination of enormous amount of non-value added activities (multiple reviews, multiple approvals, multiple handoffs, waiting times, reworking designs etc.) leading to the reduction of product development time by more than $50 \%$. It transform the culture from "firefighting" to a "problem solving" one increasing the flow of communication across the organization (enforce the discipline). It will also shift the attitude of employees towards surfacing problems and treating them as opportunities for improvement. Quick access to relevant, complete, correct amount of available knowledge without waiting escalates the dispositions resulting to improved efficiency of individuals. Finally the organization will be able to witness some intangible benefits including an enhancement in respect for culture, identity, and relations among the employees.

Even though there are evident benefits of VSM, the end user should be careful while working. VSM can be misleading for the decision maker if the current state is not captured preciously at any given time to understand the situation. In addition to this, VSM just provides the situation to explore the areas which need immediate attention for improvements. It basically does not provide any direct solution of the issues. Irrespective of both these limitations, it is a substantive concept liking tools and people allowing everyone to empathize and improve continuously regarding understanding of lean and their organization.

\section{Managerial Relevance}

Recent business trends in the competitive environment have shown that profits of a company are shaped by price and lead-time decisions (Pekgun 2007). More than half of the total expenditure is spent on wastes during PD which takes around 4-5 years for under study company ABC (Liker 2004; Kennedy 2008). With this regard, the contribution of this paper is three-fold. First relevance is to change the mind-set of employees by reorienting their thinking around the Lean philosophy. Once the employees will start to live the lean culture, the organization will start to realize more the emerged benefits (long term advantage). Second contribution is to provide a step by step approach in form of a systematic framework to the implementation of lean thinking tools in a PD. This systematic framework can be further modified, customized, or tweaked to implement tools to other efforts in same or different research domain. The third 
relevance is to improve the competitive position through wastes reduction in a PD environment to make the existing PD process leaner. This waste reductionist approach assists in reducing the lead-time and achieving cost targets with competitive advantage (short term benefit).

\section{Conclusion and Future Research}

This research discusses the objective and associated problems with product development process for a case study unit of a Gas Turbine manufacturer. Drawing from the experiences and best practices of reviewed case study, the practical strategies are described to improve product development performance achieving lean goals such as improved quality, reduced waste and shortened PD lead-time. Specifically, Value Stream Mapping based method is used to develop the current state map in order to find the wastes in the process and action plan to eliminate all the wastes to reach the future (better) state. In order to develop the current state, a Gemba walk is done in order to find the most complex and lengthy lead-time process targeted for improvement. Consequently, a brain storming session is conducted to find out the root causes of wastes. The framework is still in the implementation phase, however, the expected benefits are summarized. All the proposed changes will result in the reduction of lead time for the design stage reducing thus the overall PD lead time by 50\%. Implementation of other innovative methodologies such as Critical Chain Project Management is clearly a matter of future research. A framework exploiting the knowledge generated during process walk to store, retain and re-use is a potential research domain. In addition, the extension of VSM implementation on other critical process and finally to whole enterprise will be targeted in the future. Investigation of the human element factor in analyzing the performance of future state process is clearly a topic for future search.

\section{References}

Abdullah, F. (2003). Lean manufacturing tools and techniques in the process industry with a focus on steel (Doctoral dissertation, University of Pittsburgh).

Agarda, B., Bassetto, S., 2013. Modular design of product families for quality and cost. International Journal of Production Research, 51 (6), 1648-1667.

Anand, G., Kodali, R., 2008. Development of a conceptual framework for lean new product development process. International Journal of Product Development, 2 (6), 190-224.

Anderson, D.M., Pine, J.B., 1997. Agile product development for mass customization. Irwin 
Professional Publishing, Chicago, USA.

Ballard, G., Howell, G.A., 2003. The underlying theory of project management is obsolete. Proceedings of the PMI Research Conference, 293-302.

Bamford, D.R., Lodge, A., 2007. Health service improvement through diagnostic waiting list Management, Leadersh Health Serv, 20 (4), 254-65.

Barczak, G., Kahn K.B., 2012. Identifying new product development best practice, Business Horizons, 55 (3), 293-305.

Baumgartner, J., 2006. The step by step guide to brainstorming. http://www.jpb.com/creative/brainstorming.php

Bottger, P.C., Yetton. P.W., 1987. Improving group performance by training in individual problem solving. Journal of applied Psychology, 72 (4), 651-657.

Cai, X., Tyagi, S.K., Yang, K., 2011. Activity-based costing model for MGPD. Improving Complex Systems Today, 409-416.

Cankurtaran, P., Langerak, F., Griffin, A., 2013. Consequences of new product development speed: A meta-analysis. Journal of Product Innovation Management 30 (3), 465-486.

Clark, K.B., Fujimoto, T., 1991. Product development performance: Strategy, organization and management in world auto industry. Harvard Business School Press, Cambridge, MA, USA.

Cudney E., Elrod, C., 2010. Incorporating lean concepts into supply chain management. International Journal of Six Sigma and Competitive Advantage, 6 (1/2), 12-30.

Cusumano, M., Kahl, S., Suarez, F.F., 2012. Product, Process, and Service: A New Industry Lifecycle Model, StudyMode.com.

Demeter, K., Matyusz, Z., 2011. The impact of lean practices on inventory turnover. International Journal of Production Economics, 133 (1), 154-163

Droge, C., Jayaram, J., Vickery, S.K., 2000. The ability to minimize the timing of new product development and introduction: an examination of antecedent factors in the NA automobile supplier industry. Journal of Product Innovation Management, 17 (1), 24-40.

Fleischer, M., Liker, J., 1997. Concurrent engineering effectiveness-integrated product development across organizations. Hanser Gardner Publications, Cincinnati, USA.

Haque, B., James-moore, M., 2004. Applying lean thinking to new product introduction. Journal of Engineering Design Volume, 15 (1), 1-31. 
Herron, C., Braiden, P.M., 2006. A methodology for developing sustainable quantifiable productivity improvement in manufacturing companies. International Journal of Production Economics, 104 (1), 143-153.

Houlahan, C.J., 1994. Reduction of front-end loading of inventory: making the airframe industry lean through better inventory management. MIT, Cambridge, USA.

Huthwaite, B., 2004. The lean design solution. Institute for Lean Design, Mackinac Island, MI, USA.

Imai, K., Nonaka, I., Takeuchi, H., 1985. Managing the new product development process: How the Japanese companies learn and unlearn in the uneasy alliance. Harvard Business School Press, Cambridge, MA.

Langerak, F., Hultink, E.J., 2005. The impact of new product development acceleration approaches on speed and profitability: lessons for pioneers and fast followers. IEEE Transactions on Engineering Management, 52 (1), 30-42.

Kennedy, M.N., 2003. Product Development for the Lean Enterprise. Oaklea Press.

Kennedy, M., 2008. Ready, set, dominate. Virginia: Oaklea Press.

Khalil, R.A., Stockton, D.J. 2010. Predicting the effects of cycle time variability on the efficiency of electronics assembly mixed-model, zero-buffer flow processing lines. International Journal of Computer Integrated Manufacturing, 23(12), pp. 1149-1157.

Kotler, P., 2003. Marketing management: analysis, planning, implementation and control. Prentice-Hall, Englewood Cliffs, New Jersey, USA.

Kumar, M., Antony, J., Singh, R.K., Tiwari, M.K., Perry, D., 2006. Implementing lean sigma framework in an Indian SME: a case study, Production Planning \& Control, 17 (4), 407423.

Mascitelli, R., 2007. Lean product development guidebook-Everything your design team needs to improve efficiency and slash time-to-market. Northridge: Technology Perspectives.

Maylor, H., 1997. Concurrent new product development: an empirical assessment. International Journal of Operations and Production Management, 17 (12), 1196-1214.

McManus, H.L., 2005. Product development value stream mapping (PDVSM) manual.

The Lean Aerospace Initiative, Cambridge, MA, USA.

Millson, M.R., Raj, S.P., Wilemon, D., 1992. A survey of major approaches for accelerating new 
product development. Journal of Product Innovation Management, 9 (1), 53-69.

Morgan, J., Liker, J., 2006. The Toyota product development system: integrating people, process, and technology. Productivity Press, New York, USA.

Panizzolo, R., 1998, Applying the lessons learned from 27 lean manufacturers: The relevance of relationships management. International Journal of Production Economics, 55 (3), 223240.

Pekgun-Cakmak, P., 2007. An analysis of pricing and lead-time policies within the marketing/ operations interface. PhD dissertation, Georgia Institute of Technology.

Pool, A., Wijngaard, J., Zee, D.J., 2011. Lean planning in the semi-process industry, a case study. International Journal of Production Economics, 131 (1), 194-203.

Poppendieck, M., Poppendieck, T., 2007. Lean Software Development: An Agile

Toolkit. Addison-Wesley Professional, MA, USA.

Quinn, T.D., 2012. The implementation dynamics of continuous improvement throughout the corporate hierarchy based on lean six sigma at DTE energy. MIT, MA, USA.

Radeka, K., 2012. The mastery of innovation: a field guide to lean product development. CRC Press.

Radnor Z., Boaden, R., 2008. Lean in Public Services_Panacea or Paradox?, Public Money \& Management, 28 (1), 3-7.

Roemer, T.A., Ahmadi, R., Wang, R.H., 2000. Time-cost tradeoffs in overlapped product Development. Operations Research, 48 (6), 858-865.

Russell. R.S., Tuylor. B.W.. 1999. Operations Management. Prentice Hull: Upper Suddie River. NJ, USA.

Seth, D., Gupta, V., 2005. Application of value stream mapping for lean operations and cycle time reduction: an Indian case study. Production Planning \& Control, 16 (1), 44-59.

Shehab, A.A., Alam, E.R., Sopelana, A., Sorli, M., Flores, M., Taisch, M., Stokic, D., JamesMoore, M., 2010. The Conceptual LeanPPD Model. ISPE International Conference on Concurrent Engineering. Cracow (Poland).

Singh, B., Garg, S. K., \& Sharma, S. K. (2011). Value stream mapping: literature review and implications for Indian industry. The International Journal of Advanced Manufacturing Technology, 53(5-8), 799-809.

Simons, D., Taylor, D., 2007. Lean thinking in the UK red meat industry: A systems and 
contingency approach. International Journal of Production Economics, 106 (1), 70-81.

Smith, P.G., Reinertsen, D.G., 1998. Developing products in half the time: New rules, new tools. John Wiley \& Sons, New York, USA.

Storch R.L., Lim, S., 1999. Improving flow to achieve lean manufacturing in shipbuilding. Production Planning \& Control, 10 (2), 127-137.

Sullivan, W.G., McDonald, T.N., Aken, E.M., 2002. Equipment replacement decisions and lean manufacturing. Robotics and Computer Integrated Manufacturing, 18 (3-4), 255-265.

Syan, C.S., Menon, U., 1994. Concurrent engineering: concepts, implementation and practice. Chapman \& Hall, New York, USA.

Towner, S. J. 1994. Four ways to accelerate new product development. Long Range Planning 27 (2), 57-65.

Tyagi, S.K., Ghorpade, A., Karunakaran, K.P., Tiwari, M.K., 2007. Optimal part orientation in layered manufacturing using evolutionary stickers-based DNA algorithm. Virtual and Physical Prototyping, 2 (1), 3-19.

Tyagi, S.K., Yang, K., Verma, A., 2013. Non-discrete ant colony optimisation (NdACO) to optimise the development cycle time and cost in overlapped product development, International Journal of Production Research 51 (2), 346-361.

Tyagi, S.K., Yang, K., Tyagi, A., Dwivedi, S.N., 2011. Development of a fuzzy goal programming model for optimization of lead time and cost in an overlapped product development project using a Gaussian Adaptive Particle Swarm Optimization-based approach. Eng. Appl. of AI, 24 (5), 866-879.

Tyagi, S.K., Yang, K., Tyagi, A., Verma A. 2012. A Fuzzy Goal Programming Approach for Optimal Product Family Design of Mobile Phones and Multiple-Platform Architecture. IEEE Transactions on Systems, Man, and Cybernetics, Part C: Applications and Reviews, 42 (6), 1519-1530.

Ulrich, K.T., Eppinger, S.D., 2000. Product Design and Development. McGraw Hill, Boston, USA.

Voss, C.A., Blackmon, K., Hanson, P., Oak, B., 1995. The competitiveness of European manufacturing-a four country study. Business Strategy Review, 6 (1), 1-25.

Wheelwright, S.C., Clark, K.B., 1992. Revolutionizing product development. The Free Press, New York, USA. 
Womack, J., Jones, D., Roos, D., 1990. The machine that changed the world, Rawson Associates, New York, USA.

Womack, J.P., Jones, D.T., 2003. Lean thinking: Banish waste and create wealth in your corporation. Free Press, New York, USA.

Worley, J.M., Doolen, T.L., 2006. The role of communication and management support in a lean manufacturing implementation. Management Decision, 44 (2), 228-245.

Yang, K. 2007. Voice of the Customer Capture and Analysis. McGraw-Hill Professional, New York, USA.

Yang (Mark), M.G., Hong, P., Modi, S.B., 2011. Impact of lean manufacturing and environmental management on business performance: An empirical study of manufacturing firms. International Journal of Production Economics, 129 (2), 251-261.

Zhang, H.C., Yu, S.Y., 1997. An environmentally conscious evaluation/ design support tool for personal computers, Proceedings of IEEE International Symposium on Electronics and the Environment, San Francisco, CA, 131-136.

Zussman E., Zhou, M.A., 1999. Methodology for modeling and adaptive planning of disassembly processes. IEEE Trans. Robot Automation, 15 (1), 190-194. 